\title{
ANALISIS KESUBURAN TANAH DENGAN INDIKATOR MIKROORGANISME TANAH PADA BERBAGAI SISTEM PENGGUNAAN LAHAN DI PLATEAU DIENG
}

SOIL FERTILITY ANALYSIS WITH SOIL MICROORGANISM INDICATOR ON VARIOUS SYSTEMS OF LAND USE AT DIENG PLATEAU

\author{
Susilawati $^{1}$, Mustoyo ${ }^{1}$, Eriandra Budhisurya ${ }^{2}$, R.C.W. Anggono ${ }^{2}$, Bistok H. Simanjuntak ${ }^{3}$ \\ Diterima 9 Januari 2013, disetujui 28 Juni 2013
}

\begin{abstract}
Dieng is a plateau region, with an altitude about \pm 2095 meters above sea level. Dieng Plateau is unique land because that has low air temperature and soil dominated Andisol and has various land slope from 0 percent until $>40$ percent. Therefore, Dieng Plateau is ideal land for horticultural cultivations. The serious problem in Dieng Plateau was conducted intensively conversion the forest area to the various land use system, to example for land potatoes cultivation, settlements and tourist activity. These conditions increasing hazard for the rate soil erosion. High soil erosion rate will decrease the soil fertility.
\end{abstract}

This study aims to determine the level of soil fertility with indicators of soil microorganisms in a various of land use, given the high levels of soil erosion. The layout design of the research used is a Randomized Complete Block Design (RCBD). Analysis of the data used is Analysist of Variance ANOVA (F test), Honestly Significant Analysis (5\%) and Stepwise Regressiont. To determination the number of carbon biomass of microorganisms is applied with fumigation-extraction method. For determination of total soil microorganisms using NA media, where as the determination of soil respiration using Verstraete method.

The results showed that the land is sloping physiography (tourist land and residential) have higher fertility than high physiographic area, as a result of soil erosion. Different case for protected forests, although a high physiographic land, forests have higher fertility than the land potatos cultivation. Forest area are still natural, and its has a vegetation litter and diversity of vegetations, therefor the forest area has good barrier water runoff that carries organik material and soil salts.

Keywords : plateau Dieng, erosion, soil microorganisms, soil fertility, randomized complete block design

\section{PENDAHULUAN}

Plateau Dieng berada $26 \mathrm{~km}$ ke arah utara dari pusat kota Wonosobo. Dieng merupakan daerah dataran tinggi, dengan ketinggian rata-rata \pm 2095 meter di atas permukaan laut. Dataran tinggi Dieng terbentuk oleh kawah gunung berapi yang telah mati atau tidak aktif. Suhu udara di Dieng berkisar $14^{\circ} \mathrm{C}$ sampai dengan $20^{\circ} \mathrm{C}$ dan pada malam hari mencapai $10^{\circ} \mathrm{C}$. Pada musim kemarau suhu udara dapat mencapai $0^{\circ} \mathrm{C}$ di pagi hari (Anonim, 2010). Dari deskripsi tersebut, dataran tinggi Dieng memiliki keunikan jika dibandingkan dengan daerah lainnya. Suhu udara rendah yang dimiliki membuat Dieng sangat ideal untuk budidaya tanaman hortikultura terutama

\footnotetext{
1 Alumni Fakultas Pertanian dan Bisnis UKSW, Jalan Diponegoro 52-60 Salatiga, email: susiwu0310@ gmail.com

2 Mahasiswa Fakultas Pertanian dan Bisnis UKSW, Jalan Diponegoro 52-60 Salatiga

3 Dosen Fakultas Pertanian dan Bisnis UKSW, Jalan Diponegoro 52-60 Salatiga, email: bhasiholans@ yahoo.com
} 
Kentang, Sayuran, dan Bunga. Dieng merupakan daerah yang pem-bentukan tanahnya berasal dari letusan gunung berapi, sehingga tentu saja mikroorganisme yang terkandung di dalamnya mempunyai keunikan tersendiri.

Lahan di Dieng dialihfungsikan menjadi beberapa sistem penggunaan, seperti menjadi pemukiman, pembangunan candi (saat ini untuk wisata), lahan pertanian dan hutan. Kondisi inilah yang menjadi ketertarikan penyusun untuk menganalisis kesuburan tanah Dieng berdasarkan total mikroorganisme, respirasi tanah yang menunjukkan aktivitas mikroorganisme tanah dan biomassa karbon mikroorganisme pada beberapa sistem penggunaan lahannya.

Lima kelompok utama mikroorganisme yang terdapat dalam tanah yaitu bakteri, actynomicetes, fungi, algae dan protozoa. Jumlah bakteri yang ada dalam tanah dipengaruhi oleh berbagai kondisi yang mempengaruhi kondisi pertumbuhannya, seperti temperatur, kelembaban, aerasi dan sumber energi. Tetapi secara umum populasi yang terbesar terdapat di horizon permukaan. Jumlah dan jenis bakteri dipengaruhi oleh macam praktik pengelolaan. Di padang rumput sebagai contoh lebih besar dari pada di lahan yang diolah, karena tingginya kerapatan akar dan ketersediaan bahan organik dari dekomposisi akar dan serasah lebih banyak di daerah padang rumput (Alexander, 1977).

Clark (1967) dalam Djajakirana (1993) memperkirakan bahwa jumlah bakteri dengan perhitungan langsung adalah 2 milyiar sel.gram ${ }^{-1}$ tanah, hanya 0.2 persen dari bobot tanah. Jumlah tersebut ekuivalen dengan 4.480 kilogram bobot hidup bakteri per hektar tanah pada kedalaman $15 \mathrm{~cm}$. Sedangkan Alexander (1977) menyebutkan bahwa dengan perhitungan langsung jumlah bakteri berkisar antara beberapa ratus ribu sampai dua ratus juta bakteri.gram ${ }^{-1}$ berat tanah kering. Organisme dalam tanah selalu berubah-ubah baik jumlah ataupun aktivitasnya. Variasi jumlah dan variasi jumlah organisme dapat terjadi pada berbagai kedalaman dan tipe tanah. Beberapa faktor yang mempengaruhi antara lain struktur, tekstur dan kelembaban tanah, serta lingkungan tanah seperti aerobik dan anaerobik.

Salah satu permasalahan yang ada di Dieng adalah adanya budidaya hortikultura yang dilakukan secara intensif hingga merambah kawasan konservasi. Kondisi demikian menjadikan tingkat erosi tanah menjadi tinggi serta adanya akumulasi pestisida di beberapa badan air (sumber-sumber air yang ada). Hasil penelitian Simanjutak, et al. (2010) di lahan pertanian penanaman Kentang di Dieng, menunjukkan bahwa lahan-lahan bagian atas memiliki kandungan unsur hara yang lebih rendah dibandingkan dengan lahan-lahan di bagian bawah. Hal ini dikarenakan adanya peristiwa erosi dan terjadinya deposit tanah topsoil yang subur di lahan-lahan bagian bawah. Menurut Patra et al. (1995), beberapa faktor fisik kimia dan biologi berpengaruh terhadap dinamika hara di dalam tanah. Suhu, kelembaban dan penggunaan pupuk merupakan faktor kunci transformasi $\mathrm{C}, \mathrm{N}$ dan P. Selain itu, jenis tanaman yang tumbuh sangat nyata berpengaruh terhadap ketersediaan bahan organik dalam bentuk residu tanaman dalam tanah. Semua faktor tersebut mempengaruhi populasi mikroorganisme tanah, dan transformasi hara.

\section{Peranan Mikroorganisme Tanah pada Kesuburan Tanah}

Menurut Paul dan Clark (1989), mikroorganisme tanah merupakan faktor penting dalam ekosistem tanah, karena berpengaruh terhadap siklus dan ketersediaan hara tanaman serta stabilitas struktur tanah.

Biomassa mikroorganisme merupakan bagian yang hidup dari bahan orgnik tanah yaitu bakteri, fungi, algae dan protozoa, tidak termasuk akar tanaman dan hewan yang berukuran lebih besar dari amuba (kira-kira $5 \times 10^{3} \mu \mathrm{m}^{3}$ ) (Jenkinson dan Ladd, 1981 dalam Djajakirana, 1993). Biomassa mikroorganisme tanah mewakili 
sebagian kecil fraksi total karbon dan nitrogen tanah, tetapi secara relatif mudah berubah, sehingga jumlah, aktifitas, dan kualitas biomassa mikroorganisme merupakan fakor kunci dalam menggendalikan jumlah $\mathrm{C}$ dan $\mathrm{M}$ yang dimineralisasi (Hassink, 1994).

Menurut Lavahun (1995) biomassa mikroorganisme tanah merupakan sumber bervariasi hara-hara tanaman dan juga sebagai agen pembentukan hara-hara tersebut. Selain itu merupakan agen perombak dari semua bahan organik yang masuk ke dalam tanah, mengubahnya ke dalam bentuk senyawa anorganik sederhana, sehingga tanaman dapat menggunakannya lagi. Biomassa mikroorganisme ini memegang peranan penting dalam memelihara kesuburan tanah dan dalam siklus karbon, nitrogen, fosfor dan sulfur.

\section{Faktor-faktor yang mempengaruhi Bio- massa Mikroorganisme}

Biomassa mikroorganisme merupakan indeks kesuburan tanah. Tanah yang banyak mengandung berbagai macam mikroorganisme, secara umum dapat dikatakan bahwa tanah tersebut adalah tanah yang baik sifat fisik dan kimianya. Tingginya populasi mikroorganisme dan beragamnya mikroorganisme hanya mungkin ditemukan pada tanah yang memiliki sifat yang memungkinkan mikroorganisme tanah tersebut untuk berkembang dan aktif. Tersedianya unsur hara yang cukup, $\mathrm{pH}$ tanah yang sesuai, aerasi dan drainase yang baik, air yang cukup dan sumber energi (bahan organik) yang cukup adalah beberapa faktor yang harus dipenuhi agar mikroorganisme tanah dapat tumbuh dan ber-kembang (Iswandi et al.,1995).

Pembentukan biomassa juga dipengaruhi sejumlah faktor yang lainnya, yaitu suhu, kelembaban (Joergensen et al., 1990), dan adanya mineral liat (Ladd et al., 1981 dalam Lavahun, 1995). Selain itu faktor-faktor yang mempengaruhi kuantitas dan kualitas bahan organik tanah seperti iklim, tanaman, dan praktik pengelolaan tanah seperti rotasi tanaman, penggunaan pupuk, pengelolaan limbah tanaman dan pengolahan tanah juga ikut mempengaruhi pembentukan biomassa mikroorganisme (Henrot dan Robertson, 1994; Andersin dan Domsch, 1989, Lovell et al., 1995; Ladd et al. 1994; Granatstein et al., 1987).

Granatstein et al. (1987) mengemukakan bahwa biomassa mikroorganisme secara nyata lebih tinggi dilapisan permukaan tanah yang tidak diolah yang mempunyai residu tanaman yang cukup banyak, karena input bahan organik lebih tinggi di lapisan tersebut. Hassink (1994) menambahkan bahwa terdapat hubungan antara tekstur tanah dan biomassa mikroorganisme. Aktivitas biomassa lebih besar dua kali lipat pada tanah bertekstur pasir atau debu daripada bertekstur liat. Hal ini karena $\mathrm{C}: \mathrm{N}$ rasio pada tanah bertekstur pasir lebih tinggi dibandingkan tanah bertekstur liat.

\section{Biomassa Karbon Mikroorganisme pada berbagai tipe penggunaan lahan}

Perubahan penggunaan lahan (land-use) dan perbedaan pola tanam dapat mempengaruhi keadaan bahan organik tanah. Konversi hutan menjadi lahan pertanian menyebabakan penurunan kadar bahan organik tanah. Demikian pula, pola tanam monokultur dan rotasi dapat menyebabkan perbedaan dari bahan organik tanah (Iswandi et al.,1995). Penurunan kadar bahan organik ini akan mempengaruhi biomassa mikroorganisme tanah.

Henrot dan Robertson (1994) melaporkan bahwa konversi hutan hujan tropic menjadi padang rumput dan lahan pertanian dalam jangka panjang dapat menurunkan kandungan bahan organik tanah dan kesuburan tanah. Penurunan ini akan diikuti oleh perubahan biomassa mikroorganisme. Ditambahkan pula bahwa perubahan biomassa mikroorganisme tanah akibat penebangan hutan di daerah tropika sangat mempengaruhi kesuburan tanah. Pada tanah-tanah pertanian dapat dijumpai kandungan biomassa mikro-organisme 
sebanyak 200 - $1000 \mu \mathrm{g} . \mathrm{g}^{-1}$ tanah (Martens, 1995).

\section{BAHAN DAN METODE}

\section{Alat dan Bahan}

Bahan yang digunakan meliputi sampel tanah, Kloroform bebas-etanol, aquades, kertas saring (Whatman No.42), vaselin, $0.1 \mathrm{~N} \mathrm{~K}_{2} \mathrm{Cr}_{2} \mathrm{O}_{7}$,

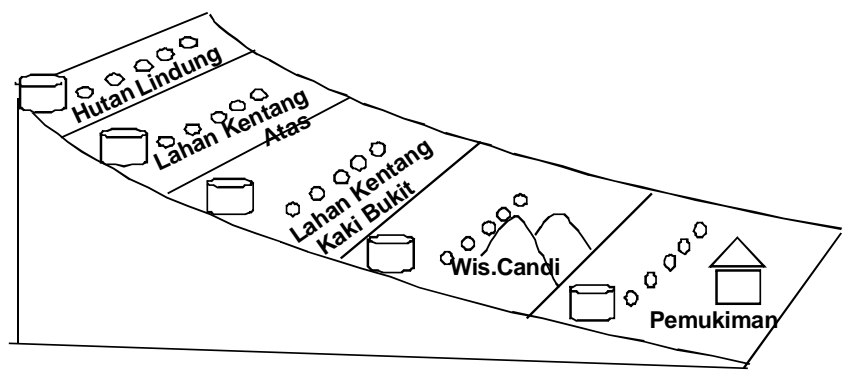
$\mathrm{H}_{2} \mathrm{SO}_{4}$ pekat, dan kertas tissu, larutan fisiologis (8.5 g NaCl dalam 11 aquades), media Nutrient Agar (NA), $0.2 \mathrm{~N} \mathrm{KOH}$, fenolftalin, $0.1 \mathrm{~N} \mathrm{HCl}$ dan metil oranye.

Alat-alat yang digunakan adalah erlenmeyer, $\mathrm{pH}$ meter, spektrofotometer, gelas ukur, pipet serologis $1 \mathrm{ml}$, tabung reaksi, botol semprot, cawan petri, enkase, autoklaf, pemanas bunsen, timbangan sartorius, toples, beaker kecil, desikator, gelas piala $50 \mathrm{ml}$, pipet $10 \mathrm{ml}$, pipet $25 \mathrm{ml}$, botol film, corong, timbangan, erlenmeyer, specimen yard dan gelas ukur.

\section{Metode Penelitian}

Pengambilan sampel tanah dilakukan di Plateau Dieng pada akhir bulan Januari 2012 sedangkan pengukuran mikroorganisme tanah untuk analisis tingkat kesuburan tanahnya dilakukan di Laboratorium Tanah, Fakultas Pertanian dan Bisnis UKSW pada awal bulan Februari 2012 sampai akhir bulan Maret 2012. Tahapan penelitian meliputi:

\section{Rancangan Penelitian}

Penelitian menggunakan layout Rancangan Acak Kelompok (RAK), yaitu dengan 5 perlakuan: a) Lahan pertanian di sekitar wisata candi, b) lahan permukiman (pekarangan), c) lahan penanaman kentahan di atas bukit, d) lahan penanaman kentang di kaki bukit, (e) lahan hutang lindung. Semua lahan diambil pada jalur transek yang sama dan dapat dilihat pada gambar 1 .

Gambar 1. Jalur Transek Pengambilan Sampel Tanah

Pada setiap perlakuan lahan dilakukan ulangan 5 $(\mathrm{r}=5)$, di mana pada setiap ulangan tersebut dilakukan pengambilan sampel tanah utuh dan tidak utuh. Adapun model matematis untuk RAK adalah sebagai berikut.

$$
\mathbf{Y}_{\mathrm{ij}}=\boldsymbol{\mu}+\mathbf{T}_{\mathrm{i}}+\boldsymbol{\beta}_{\mathrm{j}}+{ }^{{ }^{6}} \mathrm{ij}
$$

Keterangan :

Yij= hasil pengamatan perlakukan ke I dan ulangan ke $\mathrm{j}$

$\mu=$ purata umum

$\mathrm{Ti}=$ Penyimpangan hasil dari nilai purata umum yang disebabkan oleh perlakuan ke i

$\beta \mathrm{j}=$ Penyimpangan hasil dari nilai purata umum yang disebabkan oleh kelompok ke $\mathrm{j}$

‘ij = Pengaruh acak yang masuk dalam percobaan

\section{Pelaksanaan Penelitian}

a. Persiapan Tanah

Pada setiap lokasi tipe penggunaan lahan, contoh tanah diambil secara komposit sebanyak $1 \mathrm{~kg}$. Contoh tanah sebelum dan selama penelitian disimpan pada suhu rendah (dalam ice box).

b. Penetapan Biomassa $\mathrm{C}_{\text {mic }}$

Total biomassa karbon mikroorganisme $\left(\mathrm{C}_{\text {mic }}\right)$ diterapkan dengan metode fumigasi-ekstraksi (modifikasi metode Ohlinger dan Gerzabek, 1995) yang terdiri dari fumigasi, ekstraksi dan analisis ekstrak.

\section{Fumigasi}

Contoh tanah sebanyak 10 g BKM (bagian A) ditempatkan dalam gelas piala $50 \mathrm{ml}$ kemudian 
difumigasi dengan kloroform bebas-etanol selama 48 jam dan bagian $B$ sebagai control ditempatkan dalam Erlenmeyer $250 \mathrm{ml}$, langsung diekstrak dengan $50 \mathrm{ml} 0,5 \mathrm{M} \mathrm{K}_{2} \mathrm{SO}_{4}$. Fumigasi dilakukan dengan menempatkan semua gelas piala berisi contoh tanah ke dalam specimen yard yang mengandung $10 \mathrm{ml}$ kloroform bebas-etanol per contoh tanah. Katup bagian atas specimen yard ditutup dan dioles dengan vaselin serta disimpan di tempat gelap selama 48 jam. Setelah 48 jam katup specimen yard dibuka. Setelah itu setiap contoh tanah ditempatkan dalam erlenmayer 250 ml untuk diekstraksi.

\section{Ekstraksi}

Erlenmeyer yang telah berisi contoh tanah kemudian ditambahkan $50 \mathrm{ml} \mathrm{M} \mathrm{K} \mathrm{SO}_{4}$. Setelah itu dikocok selama tiga puluh menit. Selanjutnya disaring dengan menggunakan kertas saring Whatman No.42. Ekstrak tanah ditempatkan dalam botol film untuk dianalisis. Ekstrak tanah dapat ditempatkan dalam botol film untuk dianalisis. Ekstrak tanah dapat disimpan dalam lemari es pada suhu $-18^{\circ} \mathrm{C}$ sampai dianalisis.

\section{Analisis Ekstrak Tanah}

Sebanyak $10 \mathrm{ml}$ ekstrak tanah ditempatkan dalam erlenmayer $250 \mathrm{ml}$, ditambahkan $10 \mathrm{ml} 0.1 \mathrm{~N}$ $\mathrm{K}_{2} \mathrm{Cr}_{2} \mathrm{O}_{7}$ dan $10 \mathrm{ml} \mathrm{H}_{2} \mathrm{SO}_{4}$ pekat, kemudian erlenmeyer dilepaskan dan dibiarkan dingin. Setelah dingin ditambahkan $100 \mathrm{ml}$ Aquades kemudian diukur C-nya menggunakan spektrofotometer. Kontrol dan blanko diperlakukan dengan cara yang sama. Perhitungan (Hassink, 1994): $\mathrm{C}_{\text {mic }}=$ dihitung dari persamaan : $\mathrm{C}_{\text {mic }}=$ $\left(\mathrm{C}_{\text {fumigasi }}-\mathrm{C}_{\text {kontrol }}\right) \times 2.64$ (di mana 2.64 merupakan faktor konversi)

\section{c. Penetapan Total Mikroorganisme Tanah}

Tahap pertama yaitu pembuatan larutan fisiologis

(8.5 g NaCl / 1). Larutan disterilkan dengan menggunakan autoklaf, selama 20 menit pada suhu $120^{\circ} \mathrm{C}$. Tahap kedua yaitu pembuatan seri pengenceran, dengan memasukan $10 \mathrm{~g}$ tanah ke dalam erlenmeyer yang berisi $90 \mathrm{ml}$ larutan fisiologis steril, kemudian dikocok selama kurang lebih 15 menit dan setelah itu dibuat seri pengenceran sampai $10^{-6}$. Penetapan jumlah mikroorganisme tanah dengan menggunakan metode cawan tuang dengan media Nutrient Agar (NA). Pembuatan NA yaitu dengan melarutkan $10 \mathrm{~g}$ NA ke dalam 1 liter aquades dan selanjutnya diautoklaf pada suhu $120^{\circ} \mathrm{C}$ selama 15 menit. Tahap ketiga yaitu pemindahan ke dalam cawan petri secara steril dari pengenceran $10^{-5}$ dan $10^{-6}$ sebanyak $1 \mathrm{ml}$, setiap pelakukan dilakukan duplo. Setelah itu ke dalam cawan petri dituangkan media NA $\pm 10 \mathrm{ml}$. Media diinkubasikan pada suhu kamar selama dua hari.

\section{d. Penetapan Respirasi Tanah}

Penetapan respirasi tanah dilakukan dengan menggunakan metode Verstraete (Iswandi, 1989). Sebanyak $100 \mathrm{~g}$ tanah ditempatkan dalam tabung kaca 11 bersama dengan dua buah botol film yang berisi $5 \mathrm{ml} 0.2 \mathrm{~N} \mathrm{KOH}$ dan $10 \mathrm{ml} \mathrm{H}_{2} \mathrm{O}$. Tabung kaca ditutup rapat kemudian diinkubasikan ditempat gelap pada suhu kamar selama satu minggu. Pada akhir inkubasi, ditambahkan dua tetes fenolftalin ke dalam botol film yang berisi $\mathrm{KOH}$ dan dititrasi dengan $0.1 \mathrm{~N} \mathrm{HCl}$ sampai warna merah hilang, kemudian ditetesi dengan dua tetes metil oranye dan dititrasi dengan $0.1 \mathrm{~N} \mathrm{HCl}$ hingga warna berubah dari kuning menjadi merah muda. Jumlah $\mathrm{HCl}$ yang digunakan pada titrasi tahap kedua berhubungan langsung dengan jumlah $\mathrm{CO}_{2}$ yang difiksasi. Penetapan $\mathrm{CO}_{2}$ dihitung dari reaksi dengan $\mathrm{KOH}$ (Iswandi, 1989). Reaksi yang berlangsung adalah:

$$
\begin{aligned}
& \mathrm{KOH}+\mathrm{CO}_{2} \rightarrow \mathrm{K}_{2} \mathrm{CO}_{3}+\mathrm{H}_{2} \mathrm{O} ; \mathrm{K}_{2} \mathrm{CO}_{3}+\mathrm{HCl} \rightarrow \mathrm{KCl}+\mathrm{KHCO}_{3} \\
& \mathrm{KHCO}_{3}+\mathrm{HCl} \rightarrow \mathrm{KCl}+\mathrm{H}_{2} \mathrm{O}+\mathrm{CO}_{2}
\end{aligned}
$$

\section{Analisis Data}

Hasil penelitian diolah menggunakan Uji Sidik Ragam (uji F) dan untuk mengetahui pengaruh perlakuan terhadap karakteristik mikroorganisme 
tanah dilakukan Uji BNJ 5 persen dan dilakukan Uji StepWise Regresi untuk menentukan faktor dominan variabel mikroorganisme tanah yang menentukan tingkat kesuburan tanah.

\section{HASIL DAN PEMBAHASAN}

Berdasarkan Tabel 1 menunjukkan bahwa berbagai penggunaan lahan pada posisi fisiografi lahan mampu mempengaruhi karakter kadar air tanah, $\mathrm{pH}$ tanah, Bahan Organik Tanah dan Total Mikroorganisme Tanah. Namun demikian, ternyata penggunaan lahan pada posisi fisiografi lahan tidak mampu mempengaruhi nilai electrical conductivity (EC), Respirasi Tanah dan Biomasa Karbon Mikroorganisme $\left(\mathrm{C}_{\text {mic }}\right)$. bersifat basa, karena unsur hara basa mudah tercuci dan terlimpas oleh air.

\section{Bahan Organik}

Tabel 1, menunjukkan tanah hutan lindung memiliki persentase bahan organik yang lebih tinggi dibandingkan lahan Kentang atas dan lahan Kentang kaki bukit, hal ini bisa terjadi karena hutan lindung masih alami, dan terdapat banyak serasah tumbuhan, serta vegetasi-vegetasi yang ada dapat menahan limpasan air yang mengakibatkan bahan organik terakumulasi di lokasi tersebut. Untuk lahan pemukiman dan wisata mempunyai persentase bahan organik tertinggi dan tidak berbeda nyata antara keduanya. Nilai

Tabel 1. Kadar Air, pH, Persentase Bahan Organik, Electrical Conductivity (EC), Respirasi Tanah, Biomassa Karbon Mikroorganisme Tanah $\left(\mathrm{C}_{\text {mic }}\right)$ dan Total Mikroorganisme Tanah di Berbagai Tipe Penggunaan Lahan

\begin{tabular}{lcccccc}
\hline \multicolumn{1}{c}{ PERLAKUAN } & $\mathrm{pH}$ & $\begin{array}{c}\text { BO } \\
(\%)\end{array}$ & $\begin{array}{c}\mathrm{EC} \\
\left(\mu \mathrm{SS} \cdot \mathrm{m}^{-1}\right)\end{array}$ & $\begin{array}{c}\text { Respirasi Tanah } \\
\left(\mathrm{mg} \mathrm{C} \cdot \mathrm{kg}^{-1} \cdot \mathrm{hari}^{-1}\right)\end{array}$ & $\begin{array}{c}\text { Cmic } \\
\left(\mu \mathrm{\mu g} \cdot \mathrm{g}^{-1}\right)\end{array}$ & $\begin{array}{c}\text { Total } \\
\text { Mikroorganisme } \\
\left(10^{7} \mathrm{spk}^{-1}\right)\end{array}$ \\
\hline Hutan Lindung & $6,60 \mathbf{a}$ & $5,14 \mathbf{a b}$ & $72,00 \mathbf{a}$ & $5,20 \mathbf{a}$ & $869,45 \mathbf{a}$ & $1,8 \mathbf{a}$ \\
Lahan Kentang Atas & $6,88 \mathbf{b}$ & $3,79 \mathbf{a}$ & $70,00 \mathbf{a}$ & $5,84 \mathbf{a}$ & $305,14 \mathbf{a}$ & $2,6 \mathbf{a}$ \\
Lahan Kentang Kaki Bukit & $7,30 \mathbf{c d}$ & $3,58 \mathbf{a}$ & $84,00 \mathbf{a}$ & $6,56 \mathbf{a}$ & $759,12 \mathbf{a}$ & $2,9 \mathbf{a b}$ \\
Pemukiman & $7,40 \mathbf{d}$ & $5,94 \mathbf{a b}$ & $102,0 \mathbf{a}$ & $7,92 \mathbf{a}$ & $480,18 \mathbf{a}$ & $4,68 \mathbf{b}$ \\
Wisata Candi & $7,22 \mathbf{c}$ & $6,64 \mathbf{b}$ & $86,00 \mathbf{a}$ & $8,00 \mathbf{a}$ & $748,03 \mathbf{a}$ & $4,0 \mathbf{a b}$ \\
\hline
\end{tabular}

Keterangan: angka yang diikuti huruf sama menunjukkan tidak adanya beda nyata antar perlakuan dan angka yang diikuti huruf berbeda menunjukkan adanya perbedaan antar perlakuan pada uji BNJ 5\%

Berdasarkan tabel 1 di atas, terlihat bahwa 7 parameter pengukuran memiliki nilai yang berbedabeda untuk setiap lokasi sampel tanah. Berikut merupakan uraian penjelasan untuk setiap parameter pengukuran.

\section{pH}

Terdapat hubungan antara posisi fisiografi lahan dengan nilai $\mathrm{pH}$ tanah. Hal ini dikarenakan adanya proses pencucian dan limpasan (run off) unsurunsur hara (dari pupuk) lahan atas menuju lahan bawah. Pada fisiografi lahan bawah yang rendah menunjukkan nilai pH tinggi (semakin mendekati basa) yang diakibarkan dari akumulasi unsur hara pengukuran yang tinggi ini merupakan akumulasi bahan organik dari lahan Kentang atas dan lahan Kentang kaki bukit yang berada di atasnya. Oleh karena itu, persentase bahan organik pada kedua lahan tersebut (lahan Kentang atas dan lahan Kentang kaki bukit) lebih rendah.

\section{Electrical Conductivity}

Nilai electrical conductivity (EC) dapat digunakan sebagai indeks tingkat akumulasi garam pada lahan. Tabel 1 menunjukkan Nilai EC yang terukur menunjukkan terjadinya akumulasi garam dari lokasi fisiografi lahan yang tinggi ke lokasi fisiografi lahan yang rendah, dikarenakan adanya limpasan air yang membawa garam- 
garam tercuci ke fisiografi lahan yang lebih rendah dan rendah. Indikasi adanya pencucian garam juga terlihat pada nilai $\mathrm{pH}$ tanah di mana pada lahan posisi fisiografi rendah dan rendah memiliki nilai pH tinggi. Berdasarkan pada nilai EC yang ada menunjukkan nilai EC yang terukur pada semua lahan pengamatan belum melewati ambang batas yang dapat menghambat pertumbuhan mikroorganisme tanah, di mana pada nilai EC $>3,00 \mathrm{~S} /$ $\mathrm{m}$ akan mampu mempengaruhi perkembangan mikroorganisme tanah akibat adanya perubahan signifikan pada $\mathrm{pH}$ dan toksisitas.

\section{Biomassa Karbon Mikroorganisme Tanah $\left(\mathrm{C}_{\text {mic }}\right)$, Respirasi Tanah, dan Total Mikro- organisme Tanah}

Biomassa karbon mikroorganisme $\left(\mathrm{C}_{\text {mic }}\right)$, respirasi tanah dan total mikroorganisme memiliki keterkaitan satu sama lainnya. Tabel 1 menunjukkan berdasarkan hasil pengujian dengan BNJ 5 persen, lahan wisata candi dan pemukiman mempunyai respirasi tanah, biomassa karbon mikroorganisme tanah $\left(\mathrm{C}_{\text {mic }}\right)$, dan total mikro-organisme tanah yang tertinggi dan tidak berbeda nyata. Hal ini sesuai dengan persentase bahan organik kedua lahan tersebut, yang telah di bahas sebelumnya. Dapat dipastikan juga bahwa total mikroorganisme yang tinggi ini dikarenakan adanya akumulasi bahan organik dari lahan yang ada di atasnya. Bahan organik merupakan makanan (energi) bagi mikroorganisme. Oleh karena itu, lahan-lahan yang memiliki persentase bahan organik yang tinggi akan mempunyai jumlah mikroorganisme tanah yang lebih besar (lihat Gambar 2.)

\section{Hubungan Biomassa Karbon Mikroorganisme Tanah, Bahan Organik dan Nilai EC}

Biomassa Karbon Mikroorganisme Tanah $\left(\mathrm{C}_{\text {mic }}\right)$ adalah salah satu indikator kesuburan tanah. Hal ini dikarenakan nilai $\mathrm{C}_{\text {mic }}$ sangat sensitif terhadap perubahan (fisika, kimia dan biologi) yang terjadi pada lahan tersebut. $\mathrm{C}_{\text {mic }}$ merupakan total karbon (C) dari mikroorganisme tanah yang selalu terkait

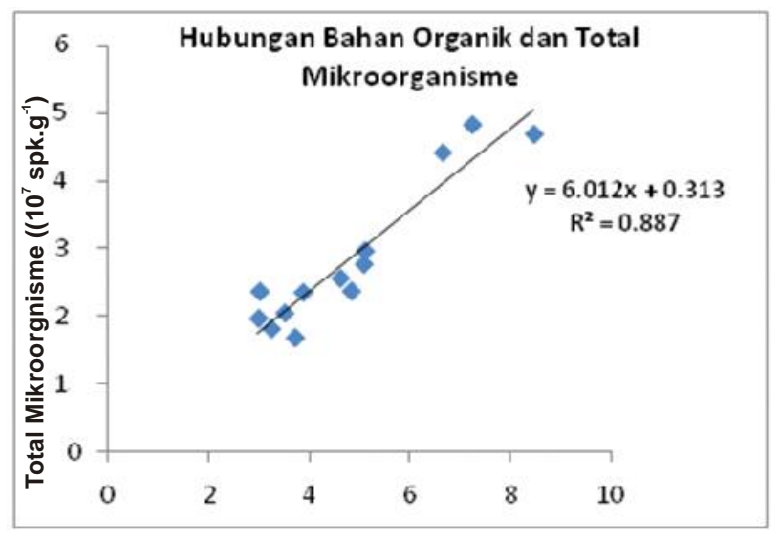

Gambar 2. Hubungan antara Bahan Organik dan Total Mikroorganisme

dengan tingkat kesuburan tanah. Tanah subur selalu memiliki nilai $\mathrm{C}_{\text {mic }}$ yang tinggi. Hal ini dikarenakan tanah yang subur selalu mampu untuk menjadi media tumbuh ideal bagi berbagai mikroorganisme (menguntungkan maupun merugikan). Tanah dengan kandungan $\mathrm{C}_{\text {mic }}$ tinggi maka akan terjadi proses dekomposisi, siklus unsur hara dan penguraian senyawa organik dan anorganik lainnya.

Berdasarkan dari Tabel 1, semua lahan yang diteliti tidak berbeda dalam nilai $\mathrm{C}_{\text {mic }}$, sehingga semua lahan pengamatan tidak berbeda tingkat kesuburannya. Namun demikian, pada lahan hutan lindung serta lahan di wisata candi memiliki nilai $\mathrm{C}_{\text {mic }}$ yang lebih baik dibandingkan dengan lahan lainnya. Kondisi ini terkait adanya akumulasi bahan organik yang sangat ideal untuk kehidupan biodiversitas mikroorganisme tanah. Hasil analisis dengan menggunakan Uji Stepwise Regresion menunjukkan bahwa besarnya Biomassa Karbon Mikroorganisme Tanah $\left(\mathrm{C}_{\text {mic }}\right)$ dipengaruhi oleh dua variabel pengamatan yaitu bahan organik dan electrical conductivity (EC). Adapun model persamaan regresi dari hasil analisis tersebut adalah:

$$
Y=1121,003+409,529 X_{1}-12,638 X_{2}
$$

Dengan: $\mathrm{Y}$ : biomassa karbon mikroorganisme $\operatorname{tanah}\left(\mu \mathrm{g} \cdot \mathrm{g}^{-1}\right)$

$\mathrm{X}_{1}$ :Bahan Organik (\%)

$\mathrm{X}_{2}$ :Electrical Conductivity $\left(\mu \mathrm{S} . \mathrm{m}^{-1}\right)$ 
Model persamaan tersebut menunjukkan bahwa tingkat kesuburan tanah dipengaruhi oleh Bahan Organik dan electrical conductivity (EC). Bahan organik mempunyai pengaruh positif yang artinya semakin banyak bahan organik dalam tanah, maka tingkat kesuburan tanah akan meningkat pula. Hal ini karena bahan organik merupakan sumber energi bagi mikroorganisme tanah untuk melakukan proses dekomposisi, siklus unsur hara dan penguraian senyawa organik maupun anorganik, sehingga menjadi faktor utama untuk meningkatkan tingkat kesuburan tanah. Sementara itu electrical conductivity (EC) mempunyai pengaruh yang negatif, di mana semakin tinggi electrical conductivity dalam tanah, maka akan menurunkan kesuburan tanah. Electrical conductivity berkaitan erat dengan $\mathrm{pH}$ tanah dan kandungan unsur hara (akumulasi garam), di mana mikroorganisme tanah pada umumnya tidak dapat bertahan hidup pada $\mathrm{pH}$ tanah yang terlalu asam maupun basa serta pada tanah dengan nilai EC tinggi. Oleh karena electrical conductivity dipengaruhi pula oleh aktivitas pemupukan (pupuk $\mathrm{N}, \mathrm{P}, \mathrm{K}$ ), sementara itu dalam penelitian ini tidak mengukur kadar $\mathrm{N}, \mathrm{P}$ dan $\mathrm{K}$ tanah, maka perlu kiranya penelitian lanjutan untuk mengetahui faktor apa yang paling mempengaruhi nilai electrical conductivity pada tanah Dieng.

\section{KESIMPULAN DAN SARAN}

\section{Kesimpulan}

Berdasarkan hasil penelitian, maka dapat disimpulkan:

1. Fisiografi lahan yang rendah $\left(\mathrm{C}_{\text {mic }}\right.$ wisata: 748,03 ( $\left.\mu \mathrm{g} \cdot \mathrm{g}^{-1}\right)$, pemukiman: 480,18 $\left.\left(\mu \mathrm{g} \cdot \mathrm{g}^{-1}\right)\right)$ memiliki kesuburan yang lebih tinggi dibandingkan fisiografi lahan yang tinggi $\left(\mathrm{C}_{\text {mic }}\right.$ lahan Kentang atas: 305,14 $\left(\mu \mathrm{g} \cdot \mathrm{g}^{-1}\right)$ dan lahan Kentang kaki bukit: 759,12 ( $\left.\left.\mu \mathrm{g} . \mathrm{g}^{-1}\right)\right)$, akibat adanya erosi tanah.

2. Berbeda halnya dengan hutan lindung $\left(\mathrm{C}_{\text {mic }}\right.$ : 869,45 ( $\left.\left.\mu \mathrm{g} \cdot \mathrm{g}^{-1}\right)\right)$, walaupun merupakan fisiografi lahan yang tinggi, hutan lindung memiliki kesuburan tanah yang lebih tinggi dibandingkan lahan Kentang atas dan lahan Kentang kaki bukit, dikarenakan masih alami dan terdapat serasah tumbuhan serta vegetasivegetasinya dapat menahan limpasan air yang membawa bahan organik serta garam-garam tanah.

3. Tingkat kesuburan tanah ditentukan oleh biomassa $\mathrm{C}_{\text {mic }}$, sementara itu biomassa $\mathrm{C}_{\text {mic }} \mathrm{di}$ plateau Dieng dipengaruhi oleh Bahan organik dan nilai electrical conductivity.

\section{Saran}

Berdasarkan hasil penelitian maka disarankan:

1. Para petani sebaiknya menerapkan teknik agronomis yang tepat pada lahan Kentang atas dan lahan Kentang kaki bukit, agar dapat menahan limpasan air (run off) yang membawa bahan organik ke lahan yang lebih rendah.

2. Selain teknis agronomis yang tepat, para petani juga perlu melaksanakan konservasi lahan dalam rangka mempertahankan kesuburan tanah.

3. Agar kesuburan tanah meningkat, maka perlu menambahkan bahan organik pada tanah.

4. Perlu penelitian lanjutan untuk melihat faktor apa yang paling dominan dalam mempengaruhi nilai electrical conductivity tanah di Dieng, sehingga dapat menjadi referensi bagi petani untuk meningkatkan kesuburan lahannya.

\section{UCAPAN TERIMAKASIH}

Terimakasih kepada Dirjen DIKTI atas hibah penelitian yang telah diberikan dalam Program Kreativitas Mahasiswa Penelitian tahun 2012.

\section{DAFTAR PUSTAKA}

Alexander, M. 1977. Introduction to Soil microbiology. Academic Press. New York. 
Anas, Iswandi. 1989. Biologi Tanah dalam Praktek. Bogor: Institut Pertanian Bogor.

Anderson, T.H. and K.H. Domsch. 1989. Ratio of microbial biomass carbon to total organik carbon in arable soils. Soil Biol. Biochem. 21: 471-479.

Anonim.2010.Letak Geografi, Astronomi dan Geologi. http://www.diengplateau.com/ 9 September 2011 4.08).

Djajakirana, G. 1993. The Ergosterol Mesurement in Soil and Fairy Ring Phenomena as an Example. Thesis. Faculty of Agriculture. George-August University.

Granatstein, D.M., D.F. Bezdicek, V.L. Cochran, L.F. Giliott and J. Hammel. 1987. Long term tillage and ratation effects on soil microbial biomass carbon and nitrogen. Biol.Fertil.Soil. 5: 265-270.

Hassink, J. 1994. Effects of soil texture on the size of the microbial biomass and on the amount of $C$ and $N$ mineralized per unit of microbial biomass in Dutch grassland soils. Soil Biol. Biochem. 26: 1573-1581.

Henrot, J. and G.P. Robertson. 1994. Vegetation removal in two soils of the humid tropics: effects on microbial biomass. Soil Biol. Biochem.26: 111-116.

Iswandi, A., D.A. Santosa dan R. Widyastuti. 1995. Penggunaan Ciri Mikroorganisme dalam Mengevaluasi Degradasi Tanah. Kongres Nasional VI HITI, 12-15 Desember 1995. Serpong.
Jenkinson, D.S. and D.S Powlson. 1976. The effect of biocidal treatments on metabolisms in soil V. A method for measuring biomass. Soil Biol Biochem. 8: 209-213.

Joergensen, R.G., P.C. Brookes and D.S. Jenkinson. 1990. Survival of the soil microbial biomass at elevated temperatures. Soil Biol. Biochem. 22:1129-1136.

Lavahun, E.M.F. 1995. Depth and Time Function of Microbial Biomass in Ploughed and Grassland Typudalfs of Lower Saxony, Germany. Thesis. The Faculty of Agriculture. George-August-University Goettingen.

Martens, R. 1995. Current methods for measuring microbial biomass $C$ in soil: potential and limitations. Biol. Fertil. Soils. 19: 87-99.

Patra, D.D., S. Chand and M. Anwar. 1995. Seasonal changes in microbial biomass in soil cropped with Palmarosa (Cymbopogon martinii L) and Japanese mint (Mentha arvensis L) in subtropical India. Biol. Fertil. Soils. 19: 193-196.

Paul, E.A. and F.E. Clark. 1989. Soil Microbiology and Biochemistry. Academic Press, Inc. London.

Simanjuntak, Bistok H., Susilawati, C.P.R Lengkong. Erik K.N., Nikolaus K.S., Adi B. 2010. Kajian Biofisik Lahan Penanaman Kentang di Dataran Tinggi Dieng. Laporan Hasil Penelitian UBCHEA dan CEMSED UKSW. Salatiga. 